\title{
Different Effectiveness of Glucagon on the Pacemaker Activity and Contractility in Intact Dog Hearts and in Isolated Perfused Right Atria
}

\author{
Yasuyuki Furukawa, M.D., Kimiaki Saegusa, M.D., \\ Yasuhiro Ogiwara, M.D., and Shigetoshi Cihiba, M.D.
}

\section{SUMmaRY}

In an isolated right atrial preparation, which was cross-perfused with heparinized arterial blood from a support dog, we investigated the effects of glucagon on heart rate and systemic arterial blood pressure of the support dog and on atrial rate and contractile force of the isolated perfused atrium when glucagon was injected into the external jugular vein of the support dog or into the sinus node artery of the isolated atrial preparation. Glucagon (0.3 to $3 \mu \mathrm{g} / \mathrm{Kg}$ i.v.) to the support dog dose-dependently induced a prominent increase in heart rate and a small increase in systemic arterial blood pressure. In the isolated, perfused atrium, marked positive chronotropic and slight, but significant, positive inotropic effects were evoked dose-dependently $1.5 \mathrm{~min}$ after intravenous injection of glucagon. These positive effects were not altered significantly by propranolol ( $1 \mathrm{mg} / \mathrm{Kg}$ i.v.). Direct injection of glucagon into the sinus node artery of isolated atria also induced marked positive chronotropic and small positive inotropic effects dose-dependently. $\mathrm{CF} / \mathrm{HR}$ ratios, inotropic effect per chronotropic effect in isolated atria, of glucagon injected intravenously or intraarterially were less than 0.7 and they were much less than those of norepinephrine (more than 3.6). These results confirm that glucagon injected intravenously or regionally produces a prominent positive chronotropic effect and a small positive inotropic effect and suggest that glucagon may be less effective as a cardiotonic agent.

\section{Additional Indexing Words:}

CF/HR ratio Contractility Glucagon Intact dog heart Isolated atrium Pacemaker activity Japan.

From the Department of Pharmacology, Shinshu University School of Medicine, Matsumoto,

Address for reprint: Shigetoshi Chiba, M.D., Department of Pharmacology, Shinshu University School of Medicine, Matsumoto 390, Japan.

Received for publication May 22, 1985.

Manuscript revised November 5, 1985. 
GINCE Farah and Tuttle ${ }^{1)}$ reported increases in rate and contractile force $D$ due to glucagon in several species, many investigators have presented the effects of glucagon on the cardiovascular system. Recently, Farah ${ }^{21}$ reviewed the actions of glucagon on the cardiovascular system and described several factors, i.e., species, cardiac conditions, age, etc., that influenced the effects of glucagon on the heart. Although Farah and Tuttle ${ }^{1)}$ observed the effects of glucagon only in isolated heart tissues and not in the anesthetized dog heart, the positive cardiac action of glucagon has been observed in the anesthetized dog heart by others. ${ }^{3-8)}$ In 1975, Chiba ${ }^{9)}$ showed that the chronotropic and inotropic effects of glucagon were different from those of norepinephrine in the isolated dog atrial preparation. MacLeod et al ${ }^{10)}$ reported that the effect of glucagon on the contractile force of atria was greater than that on the papillary muscles in the guinea-pig and that the difference between atria and papillary muscles was in parallel with changes in cyclic AMP. There were some differences between the effects of glucagon on isolated heart preparations and on intact hearts. In the isolated, blood-perfused dog atrial preparation, the same drug concentration in the support dog will also be present in the isolated atrium which is perfused with the support dog's blood. Therefore, direct cardiac effects in isolated atria and hemodynamic effects in support dogs might be observed simultaneously when the substance is administered to the support dogs.

The present study of the isolated dog right atrial preparation, cross-perfused with arterial blood from a support dog, was designed to determine the differences in cardiac responses to glucagon injected into the external jugular vein of the support dog or injected into the sinus node artery of the isolated atrium, and to analyze regional differences in the effects of glucagon on pacemaker activity and atrial contractility.

\section{Methods}

Isolated atria were obtained from 13 mongrel dogs and each preparation was perfused with arterial blood from an anesthetized support dog. The details of this preparation have been described previously. ${ }^{11,12)}$

The support dogs, which weighed 10 to $30 \mathrm{Kg}$, were anesthetized with sodium pentobarbital ( $30 \mathrm{mg} / \mathrm{Kg}$ i.v.). Sodium heparin (500 USP units/Kg) was administered intravenously to each dog at the beginning of the perfusion and 200 USP units/Kg were given each hour thereafter. The recipient dogs weighed 8 to $22 \mathrm{Kg}$ and they also were anesthetized with sodium pentobarbital. Heparin (200 USP units/Kg i.v.) was given and the right atria were excised and immersed in cold Tyrode's solution. The wet weights of the isolated 
right atrial preparations varied from 6 to $16 \mathrm{Gm}$. In each preparation, the sinus node artery was cannulated via the right coronary artery and was perfused with blood conducted from the carotid artery of the support dog with the aid of a peristaltic pump (Harvard Apparatus model 1210). A pneumatic resistance was placed in parallel with the perfusion system so that the perfusion pressure could be maintained constant at $100 \mathrm{mmHg}$. The blood flow rate of the isolated atrium was 3 to $9 \mathrm{ml} / \mathrm{min}$. The venous effluent from the preparation was led to a collecting funnel, from which it was returned continuously to the support dog via an external jugular vein.

The ventricular margin of the atrium was attached to a rigid stainless steel bar and the preparation was placed in a glass container. The superior part of the atrium was connected to a force transducer (Nihon Kohden AT600G) by silk thread. The atrial muscle was usually stretched to a resting tension of $2 \mathrm{Gm}$. The isometric tension was recorded on a direct-writing rectigraph (Nihon Kohden). A pair of electrodes, placed on the atrial free wall, was used to record the electrogram. The atrial rate was derived from the atrial electrogram. Heart rate derived from ECG (lead II) and femoral arterial blood pressure of the support dog were also recorded on the rectigraph.

Drugs used in the present study were glucagon (Novo Ind. A/S), norepinephrine hydrochloride (Sankyo) and propranolol hydrochloride (Sigma). Each drug was dissolved in physiological saline. The drug was injected into the external jugular vein of the support dog or into the sinus node artery of the isolated atrium. Data were analyzed by a paired $t$-test.

\section{Results}

Effects of glucagon, injected intravenously into the support dog, on heart rate and systemic arterial blood pressure of the support dog and on atrial rate and contractile force of isolated, blood-perfused atrium

When glucagon at a dose of $3 \mu \mathrm{g} / \mathrm{Kg}$ was injected intravenously into the support dog, a prominent increase in heart rate from 152 beats/min to 203 beats/min and a small increase followed by a negligible decrease in systemic arterial blood pressure were observed as shown in Fig. 1 (left, upper panel). One and a half min after an intravenous injection of glucagon, a marked increase in atrial rate (117 to 154 beats/min) and a slight increase in atrial contractile force (5.0 to $5.6 \mathrm{Gm}$ ) were usually observed (Fig. 1; left, lower panel). These effects of glucagon on the support dog and on the isolated perfused atrial preparation were dose-dependent at doses of 0.3 to $3 \mu \mathrm{g} / \mathrm{Kg}$ i.v. in 5 experiments (Fig. 2). The positive chronotropic effect of glucagon at a dose of $3 \mu \mathrm{g} / \mathrm{Kg}$ i.v. lasted more than $30 \mathrm{~min}$. 
The effects of propranolol were investigated on the cardiovascular responses to glucagon injected into the support dog in 4 experiments. After propranolol inhibited the effects of norepinephrine on the heart, the accelerating effects of glucagon on the support dog and on the isolated atrial prepara-

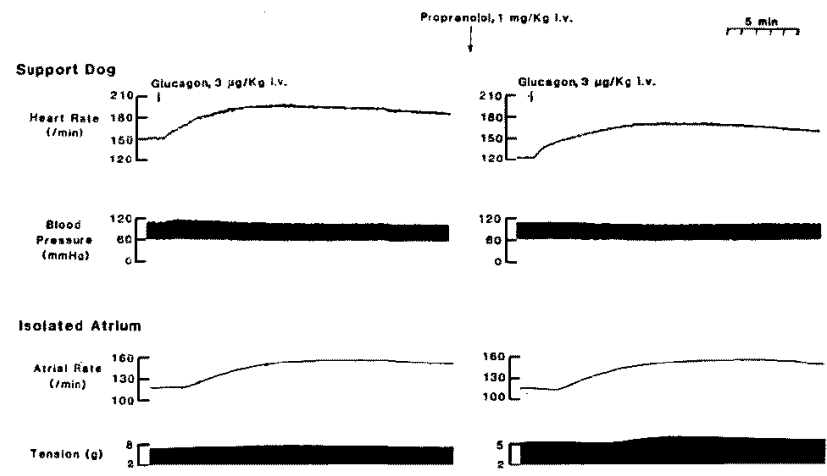

Fig. 1. The changes in heart rate and systemic arterial blood pressure of a support dog (upper panel) and in atrial rate and contractile force of an isolated, blood-perfused dog atrium (lower panel) elicited by intravenous injection of glucagon at a dose of $3 \mu \mathrm{g} / \mathrm{Kg}$ before (left panel) and after (right panel) treatment with $1 \mathrm{mg} / \mathrm{Kg}$ i.v. of propranolol.

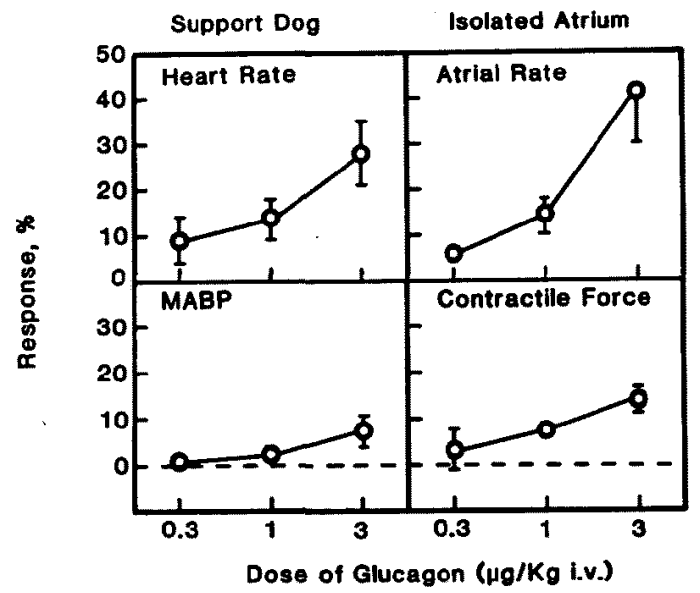

Fig. 2. Glucagon-induced dose response curves of the mean percent changes in heart rate and mean arterial blood pressure of the support dog and in atrial rate and contractile force of the isolated atrium in 5 experiments. Glucagon was injected intravenously at a dose of 0.3 to $3 \mu \mathrm{g} / \mathrm{Kg}$. The control levels of heart rate and MABP in 5 support dogs were $131 \pm 9.3$ (mean \pm SEM) beats $/ \mathrm{min}$ and $100 \pm 19.8 \mathrm{mmHg}$, respectively, and the control levels of atrial rate and contractile force in 5 isolated atria were $103 \pm 7.0$ beats/min and $2.6 \pm 0.34 \mathrm{Gm}$, respectively. Vertical bars show $\mathrm{SEM}$. MABP $=$ mean arterial blood pressure. 


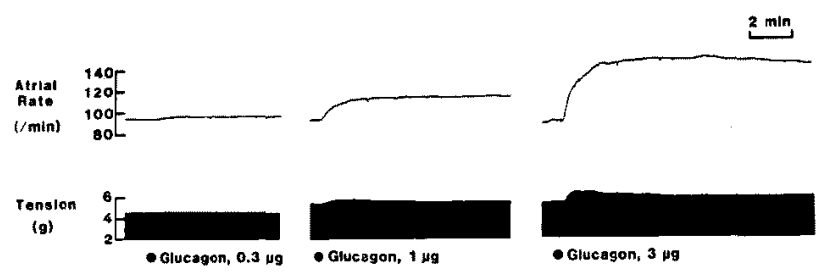

Fig. 3. The changes in atrial rate and contractile force responses to glucagon at a dose of $0.3,1$ and $3 \mu$ g injected into the sinus node artery of an isolated, blood-perfused dog atrium.

tion were not changed (Fig. 1; right panel). After treatment with propranolol ( $1 \mathrm{mg} / \mathrm{Kg}$ i.v.), the basal heart rate of the support dog decreased but blood pressure changed only slightly (Fig. 1; right, upper panel). In the isolated atrium, the basal atrial rate decreased slightly and the basal contractile force was reduced from 5.0 to $3.2 \mathrm{Gm}$ (Fig. 1 ; lower panel).

Direct effects of glucagon, injected into the sinus node ortery, on atrial rate and contractile force in the isolated, blood-perfused dog atrium

Representative responses to glucagon at doses of $0.3,1$ and $3 \mu \mathrm{g}$ injected into the sinus node artery of an isolated, perfused dog atrium are presented in Fig. 3. Glucagon at a dose of $0.3 \mu \mathrm{g}$ induced a positive chronotropic response but not a positive inotropic response. Increasing the dose of glucagon, a prominent positive chronotropic and a slight positive inotropic response were observed. When glucagon at a dose range of 0.1 to $10 \mu \mathrm{g}$ was injected into the sinus node artery of the isolated atrium, a similar prominent positive chronotropic and a small, but significant, positive inotropic effect were induced dose-dependently in 5 experiments. When an isolated atrial muscle was paced at a frequency of $2 \mathrm{~Hz}$, glucagon also induced a small positive inotropic effect in 2 experiments.

\section{Discussion}

Farah and Tuttle') observed positive chronotropic and inotropic effects in the isolated hearts of the cat, guinea-pig and rat, but not in isolated rabbit hearts. They also reported the positive chronotropic and inotropic effects of glucagon in the heart-lung preparation of the dog but not in the intact anesthetized dog. It was subsequently reported that in the anesthetized dog, glucagon increased heart rate and contractile force. ${ }^{3)-8)}$ We confirmed in the present study that both in anesthetized dogs and in isolated, blood-perfused right atrial preparations, glucagon evoked an increase in heart rate and increases in atrial rate and in contractile force, respectively. The positive car- 
diac effects in the support dog and in the isolated atrium were not inhibited by propranolol in the present experiments. The results agree with other observations. ${ }^{41,5), 91,131,14)}$ The positive inotropic response to glucagon in spontaneously beating isolated atria was small in comparison with the positive chronotropic response. However, the positive inotropic response was still observed even when the isolated atrial preparation was paced electrically. Therefore, a slight positive inotropic response to glucagon might be induced by glucagon itself, although it was partially induced by a frequency-dependent increase in contractile force as reported. 21,13$), 15), 16$ )

Lucchesi ${ }^{5)}$ studied the cardiac actions of glucagon in the open-chest, pentobarbital anesthetized dog and reported that $2 \mu \mathrm{g} / \mathrm{Kg}$ i.v. of glucagon induced about a $30 \%$ increase in heart rate. On the other hand, Tarnow et al ${ }^{7 /}$ used $40 \mu \mathrm{g} / \mathrm{Kg}$ i.v. of glucagon in the halothane-nitrous oxide anesthetized dog to induce effects similar to those observed by Lucchesi. Our experiments showed that $3 \mu \mathrm{g} / \mathrm{Kg}$ i.v. of glucagon evoked approximately a $30 \%$ increase in heart rate in the pentobarbital anesthetized dog. The difference in the dose of glucagon used to induce almost the same effect suggests that the anesthetic condition changes the effects of glucagon on the cardiac function in the dog.

A regional difference, i.e., the chronotropic effect of glucagon was greater than its inotropic effect, was reported in the isolated perfused dog atrium.9) In order to study the regional difference in pacemaker activity and atrial contractility, we calculated the $\mathrm{CF} / \mathrm{HR}$ ratio, i.e., the maximal increase in contractile force per maximal increase in heart rate, and compared the ratios of

Table I. Ghronotropic and Inotropic Effects of Glucagon or Norepinephrine on the Isolated, Blood-Perfused Dog Atrium Following Injection of Each Substance into the External Jugular Vein (i.v.) of the Support Dog or into the Sinus Node Artery (i.a.) of the Isolated Perfused Atrial Preparation

\begin{tabular}{|c|c|c|c|c|c|}
\hline & & No. of exp. & $\begin{array}{l}\text { Heart rate } \\
(\mathrm{HR}, \%)\end{array}$ & $\begin{array}{l}\text { Contraction } \\
(\mathrm{CF}, \%)\end{array}$ & $\mathrm{CF} / \mathrm{HR}$ ratio \\
\hline \multicolumn{6}{|l|}{ Glucagon } \\
\hline i.v. & 1.0 & $\mathrm{n}=5$ & $13.0 \pm 2.9$ & $7.2 \pm 1.1$ & $0.7 \pm 0.19$ \\
\hline$(\mu \mathrm{g} / \mathrm{Kg})$ & 3.0 & $\mathrm{n}=5$ & $46.4 \pm 6.9$ & $14.0 \pm 3.4$ & $0.3 \pm 0.08$ \\
\hline i.a. & 1.0 & $\mathrm{n}=4$ & $31.8 \pm 10.1$ & $13.3 \pm 1.1$ & $0.5 \pm 0.12$ \\
\hline$(\mu \mathrm{g})$ & 3.0 & $n=5$ & $57.4 \pm 8.4$ & $18.0 \pm 3.4$ & $0.4 \pm 0.11$ \\
\hline \multicolumn{6}{|c|}{ Norepinephrine } \\
\hline $\begin{array}{l}\text { i.v. } \\
(\mu g / K g)\end{array}$ & 1.0 & $\mathbf{n}=5$ & $12.4 \pm 3.0$ & $48.4 \pm 13.4$ & $4.4 \pm 1.04$ \\
\hline i.a. & 0.03 & $n=5$ & $27.0 \pm 5.8$ & $80.8 \pm 12.5$ & $3.6 \pm 0.39$ \\
\hline$(\mu \mathrm{g})$ & 0.1 & $\mathrm{n}=4$ & $36.0 \pm 5.3$ & $147.0 \pm 20.4$ & $4.1 \pm 0.15$ \\
\hline
\end{tabular}

Data show mean \pm SEM. 
glucagon to those of norepinephrine (Table I). When glucagon was injected into the external jugular vein of support dogs or into the sinus node artery of isolated atria, the $\mathrm{CF} / \mathrm{HR}$ ratios of glucagon in the isolated perfused atrium were less than 0.7 and there was not much difference in ratios between the different routes of administration of the drug. On the other hand, the $\mathrm{CF} /$ HR ratios of norepinephrine were greater than 3.6. The ratios of norepinephrine injected intravenously did not differ from those of norepinephrine injected intra-arterially, either. MacLeod et al ${ }^{10}$ ) showed a regional difference in the effect of glucagon on the contractile force of the left atria and papillary muscles of the guinea-pig. They postulated that the regional difference was parallel to changes in cyclic AMP levels in cardiac muscles. On the other hand, Henry et $a^{17}$ r reported that glucagon produced increases in contractility of a similar magnitude in both rat and guinea-pig isovolumic hearts, but increased cyclic AMP levels only in the rat heart. It has been well recognized that adrenergic stimulants cause an increase in heart rate and contractile force, simultaneously. The stimulation of $\beta$-adrenoceptors causes an activation of adenylate cyclase which in turn induces an increase in intracellular cyclic AMP levels. ${ }^{18), 19)}$ Thus, it is still difficult to understand that changes in heart rate and contractile force to adrenergic agonists are fully explained by changes in intracellular cyclic AMP levels.

The GF/HR ratios of isoproterenol, dopamine, or dobutamine in the isolated perfused atrial preparation were similar to those of norepinephrine. $\left.{ }^{20}\right)$ It is desirable for a cardiotonic agent to produce a greater increase in contractility and a lesser increase in heart rate. Although there have been attempts to use glucagon as a cardiotonic agent, ${ }^{21,21), 22)}$ its use in this indication should be limited. A typical cardiotonic agent, ouabain, at a high dose induces a marked increase in contractility and only a small increase in atrial rate in isolated dog atria, showing only an increase in contractility at an effective dose. ${ }^{23)}$

The $\mathrm{CF} / \mathrm{HR}$ ratios of glucagon calculated from the results of Lucchesi ${ }^{5}$ and Tarnow et $\mathrm{al}^{71}$ were almost 1.0 in the anesthetized dog experiments and their ratios were greater than ours (less than 0.7 ) in the isolated heart. The $\mathrm{CF} / \mathrm{HR}$ ratios of glucagon of the isolated dog atrium might exclude the extracardiac effects of glucagon. Therefore, one reason for the difference in $\mathrm{CF} / \mathrm{HR}$ ratios might be that hemodynamic changes, including reflex induced changes modify the effects of glucagon on the heart.

\section{REFERENCES}

1. Farah A, Tuttle R: Studies on the pharmacology of glucagon. J Pharmacol Exp Ther 129: 49, 1960 
2. Farah A: Glucagon and the circulation. Pharmacol Rev 35: 181, 1983

3. Whitehouse FW, James TN: Chronotropic action of glucagon on the sinus node. Proc Soc Exp Biol Med 122: 823, 1966

4. Glick G, Parmley WW, Wechsler AS, Sonnenblick EH: Glucagon: its enhancement of cardiac performance in the cat and dog and persistence of its inotropic action in spite of betareceptor blockade with propranolol. Circ Res 22: 789, 1968

5. Lucchesi BR: Cardiac actions of glucagon. Circ Res 22: 777, 1968

6. Urthaler F, Isobe JH, James TN: Comparative effects of glucagon on automaticity of the sinus node and atrioventricular junction. Am J Physiol 227: 1415, 1974

7. Tarnow VJ, Gethmann JW, Patschke D, Weymar A, Eberlein H: Haemodynamik, Koronardurchblutung und Sauerstoffverbrauch des Herzens unter Glukagon. Arzneim-Forsch 25: 1906,1975

8. Stuesse SL, Levy MN, Zieske H: Effects of glucagon on cardiac chronotropic response to vagal stimulation in the dog. Am J Physiol 242: H7, 1982

9. Chiba S: Positive chronotropic and inotropic effects of glucagon on the canine isolated atrium. Tohoku J Exp Med 115: 61, 1975

10. MacLeod KM, Rodgers RL, McNeill JH: Characterization of glucagon-induced changes in rate, contractility and cyclic AMP levels in isolated cardiac preparations of the rat and guinea pig. J Pharmacol Exp Ther 217: 798, 1981

11. Chiba S, Kimura T, Hashimoto K: Muscarinic suppression of the nicotinic action of acetylcholine on the isolated, blood-perfused atrium of the dog. Naunyn-Schmiedeb Arch Pharmacol 289: 315, 1975

12. Chiba S, Yabuuchi $\mathrm{Y}$, Hashimoto $\mathrm{K}$ : Comparison of the effects of norepinephrine and acetylcholine between intraarterial and extravascular administration of the isolated, bloodperfused canine atrium. Jpn J Pharmacol 25: 433, 1975

13. Spilker B: Comparison of the inotropic response to glucagon, ouabain and noradrenaline. Br J Pharmacol 40: 382, 1970

14. Peterson A, Lucchesi B, Kirsh MM: The effect of glucagon in animals on chronic propranolol therapy. Ann Thorac Surg 25: 340, 1978

15. Koch-Weser J, Blinks JR: The influence of the interval between beats on myocardial contractility. Pharmacol Rev 15:601, 1963

16. Chiba S: Effect of pentobarbital, verapamil and manganese on the frequency-force relationship of the isolated atrium and ventricle of the dog heart. Eur J Pharmacol 40: 225, 1976

17. Henry PD, Dobson JG, Sobel BE: Dissociation between changes in myocardial cyclic adenosine monophosphate and contractility. Circ Res 36: 392, 1975

18. Murad F, Ghi YM, Rall TW, Sutherland EW: Adenyl cyclase. III. The effects of catecholamines and choline esters on the formation of adenosine- $3^{\prime}, 5^{\prime}$-phosphate by preparations from cardiac muscle and liver. J Biol Chem 237: 1234, 1962

19. Robison GA, Butcher RW, Sutherland EW: Adenyl cyclase as an adrenergic receptor. Ann NY Acad Sci 139: 703, 1967

20. Chiba S, Watanabe H, Kobayashi M, Iwatsuki K: Cardiovascular effects of dobutamine, dopamine and isoproterenol on the whole and isolated cross-perfused atrium in dogs. Jpn J Pharmacol 33: 113, 1983

21. Parmley WW, Glick G, Sonnenblick EH: Cardiovascular effects of glucagon in man. New Engl J Med 279: 12, 1968

22. Parmley WW, Sonnenblick EH: A role for glucagon in cardiac therapy. Am J Med Sci 258: 224,1969

23. Chiba S, Furukawa Y, Kobayashi M: Direct positive chronotropic and inotropic effects of ouabain in the isolated and blood-perfused canine atrium. Jpn Heart J 19: 877, 1978 